\title{
Perception of Women on the Psychosocial Effects of Infertility
}

\author{
Akpor $\mathrm{OA}^{1}$, Fadare $\mathrm{RI}^{1}$ and Adebusuyi $\mathrm{OS}^{2}$ \\ ${ }^{I}$ Department of Nursing, College of Health Sciences, AfeBabalola University, Ado Ekiti, Nigeria \\ ${ }^{2}$ School of Health Sciences, National Open University of Nigeria, Akure Study Centre, Nigeria
}

\begin{abstract}
This aim of this study was to determine the knowledge of child bearing women on preventive measures of infertility in order to impact knowledge in area of deficiencies and to determine psychosocial effects of infertility on women. A descriptive non- experimental study was used and self-designed questionnaire was administered for data collection. Simple random technique was used to select 80 respondents. The majority of the respondents has a good knowledge on the causes and preventive measures of infertility, but still held to the misconceptions about the cause of infertility. Also, most of the respondents expressed feeling of low self-esteem as a result of infertility, this is corroborated by these findings: $57.5 \%$ of the respondents agreed that they certainly felt useless at times, $37.5 \%$ strongly agreed, $3.8 \%$ disagreed, while $1.2 \%$ of the respondents strongly disagreed. Majority of the respondents were socially isolated, this is corroborated by these findings: $11.2 \%$ of the respondents agreed that they do know what is happening with family and friends, $16.3 \%$ strongly agreed, $25 \%$ disagreed, while $47.5 \%$ of the respondents strongly disagreed. In conclusion, the study revealed sociocultural factors and lack of psychological support from the in-laws as the major factors influencing perception of psychosocial effects infertility among child bearing women.
\end{abstract}

Keywords: infertility, perception, psychosocial, women of child bearing

\section{Introduction}

According to the World Health Organization (WHO), female infertility is defined as the inability of a woman of reproductive age to conceive and carry a pregnancy to live birth within two years of exposure to the risk of pregnancy [1]. Infertility is also defined as the failure to conceive after 12 months of adequate exposure to sex without the use of contraceptives [2]. Although infertility is not always a female issue, for most Africa women, infertility produces social consequences.

In most women in Africa, the desire for children is sometimes stronger than self interest in beauty and figure, and may be stronger than the claims of a career [3]. This is because women receive more blame for reproductive setback and suffer personal grief and frustration, social stigma and serious economic deprivation. Infertility is deeply associated with socio-cultural factors, thus, it is beyond the clinical. It does not always refer to as the inability to give birth to a child. In some cases, infertility may mean inability to have the desired number of children, not having sons or not being pregnant soon after the commencement of sexual activity constitutes infertility within some cultures [4]. Historically, producing many children has been a woman's way of managing her social, economic and psychological position in Africa because it ensures continued access to land. Individuals that are perceived to be infertile often experience emotional problems, which may lead to continuous and recurring emotional feeling of inadequacy, guilt, loss, hopelessness, anxiety and a decrease in self-esteem. The majority of the individuals and couples experiencing infertility also experience internal and external pressures which increasingly affects the way they relate with each another, with families, friends and the society [5][6].

The prevalence of women diagnosed with infertility is approximately $13 \%$, with a range from $7 \%-28 \%$, depending on the age of the woman. It has remained stable for the past forty years, with ethnicity and race appearing to have little effect on prevalence. However, the incidence of primary infertility has increased, probably due to the social changes such as delayed childbearing. In normal fertile couple that is having frequent intercourse, the fecundity is estimated to be approximately $20 \%-25 \%$. Approximately $90 \%$ of couples with unprotected intercourse will conceive within one year. In Nigeria, most women with infertility are experiencing both internal and external pressures from family and the society at large. They are observed to be distanced, socially isolated from family and friends due to the perceived psychosocial effects associated with infertility[7]. Therefore this research tends to explore the perception of women on the psychosocial effects of infertility.

\section{Theoretical Framework}

The theoretical framework for this study was the Total-Person Model[8]. The model incorporates a holistic concept and an open system approach. The holistic concept described a person as a dynamic composite of physical/physiological, socio-cultural and psychological, developmental and spiritual variables that function as an open system. As an open system, a person interacts with, adjusts to and is adjusted by the environment which is viewed as a stressor. Stressor disrupts the system. The environment is a force which surrounds a person and with which they interact at any given time that affect their well-being. Neumann identified a created environment which is an environment that is created and developed unconsciously by the client and is symbolic of system wholeness.

Based on the model, infertile women have physical/physiological, psychological, socio-cultural, developmental and spiritual variables that function as an open system. By application to this study, all of these aspects of an infertile woman are inextricable intertwined with three stressors that affect the infertile woman, which are intra-personal stressor (infertility problem), inter-personal stressor (in-laws, husband and societal pressure and expectations which adversely affect infertile women) and extra-personal stressor (economic consequences of infertility).

Neumann identified a created environment, which in this study could refer to the environment that is created and developed unconsciously by the women experiencing infertility, which consequently isolate them from the society. The three 
levels of prevention identified by Neumann are primary, secondary and tertiary. The primary prevention: This focuses on strengthening a line of defense through the identification of actual or potential risk factors such as excessive drinking of alcohol beverages, smoking sexually transmitted diseases, associated with stressor. The secondary prevention strengthens the internal defense and resources by establishing treatment plan for infertility including psychotherapeutic intervention while the tertiary prevention is strengthens resistances to stressor through educating of infertile women and assist in preventing a recurrence of the stress response.

\section{Methodology}

This study was carried out using a descriptive research design. The context of the study was the Federal Medical Centre,Owo in Ondo State, Nigeria. The target population for this study was child bearing women who visit the infertility clinic at Federal Medical Centre,Owo. A total of eighty participants were selected using simple random sampling technique. The instrument for data gathering was self-designed questionnaire. The questionnaire was divided into three sections (demographic data, knowledge of infertility and psychosocial effects of infertility).

In an effort to ensure that the research instrument measures what it is intended to measure, the content validity of the research instrument was given to the researcher's supervisor and experts in medical research to scrutinize and ascertain its validity. Their observations and suggestion were to revise the instrument. In order to ensure that the research instrument maintain consistency in measuring what it intended to measure, test retest method was used, a pilot study of $10 \%$ of the sample size was carried out among child bearing women attending infertility clinic in Federal Medical Centre Owo. The questionnaire was administered to the respondents twice at two weeks interval and a Crouchback's alpha estimate was calculated for the instrument. An alpha of 0.74 was obtained and then the questionnaire was reviewed and structured. Data analysis was done using descriptive statistics like percentage, frequency tables and charts while hypothesis were tested using chi - square statistic at 0.05 level of significance.

For ethical consideration, a letter of permission to administer the questionnaire was obtained from the management of Federal Medical Centre, Owo and it was submitted to the ethical committee of the Centre, who issued the ethical clearance. Before commencement of the study, written and verbal informed consent was sought and obtained from participants. Participation was made voluntary without coercion, manipulation or undue inducement. The participants were told that they could freely withdraw at any point during the study process. The researcher administered the questionnaire to the participants. The questionnaires were retrieved from the participants immediately after completion.

\section{Interpretation of Findings}

With respect to the demographic profile of the respondents, the majority $(50 \%)$ were within age of 35-45 years while 43.7 and $6.3 \%$ of them were betweenage ranges of 25-34 years and 15-24 years, respectively. All the respondents were married.A total of $45.8 \%$ of the respondents were Muslims, while $56.3 \%$ were Christians.About $75.0 \%$ of the respondents had tertiary education while $18.8 \%$ and $6.3 \%$ had secondary and primary educational qualifications, respectively. As regards the years of infertility experience of the respondents, $5(6.25 \%)$ of them had experienced infertility for between 1-5 years while $45(56.25 \%$ ) had experienced infertility for between 11-15years (Fig. 1).

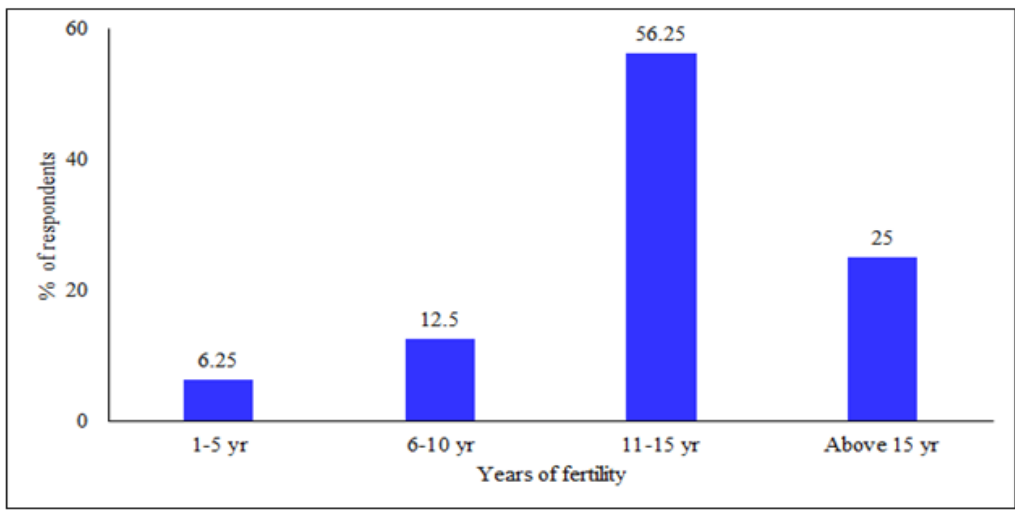

Fig.1: Years of infertility of the respondents

The majority of the respondents $(68.8 \%)$ claimed that infertility is caused by the use of contraceptives $81.2 \%$ claimed that sexually transmitted disease is a possible cause of infertility. A total of $93.8 \%$ and $90 \%$ of the respondents indicated that infertility is caused by septic abortion and getting married later than 35 years, respectively (Fig. 2).

As shown in Fig. 3, 12.5\% of the respondents agreed that they felt satisfied with themselves. Some of the respondents $(25.0 \%)$ agreed that they were able to do things as well as most other people, while the majority (48.8\%) strongly agreed. A total of $6.2 \%$ of the respondents agreed that they felt that they were persons of worth, while $18.7 \%$ agreed that they took positive attitude towards themselves (Fig. 3). 


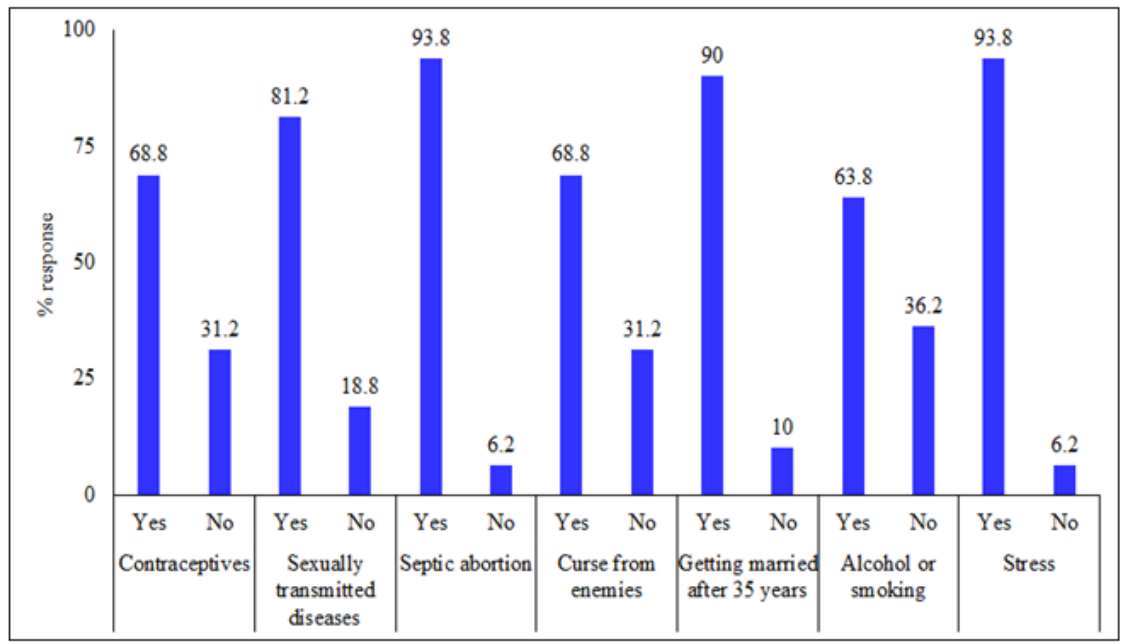

Fig. 2: Respondents' perceived causes of infertility

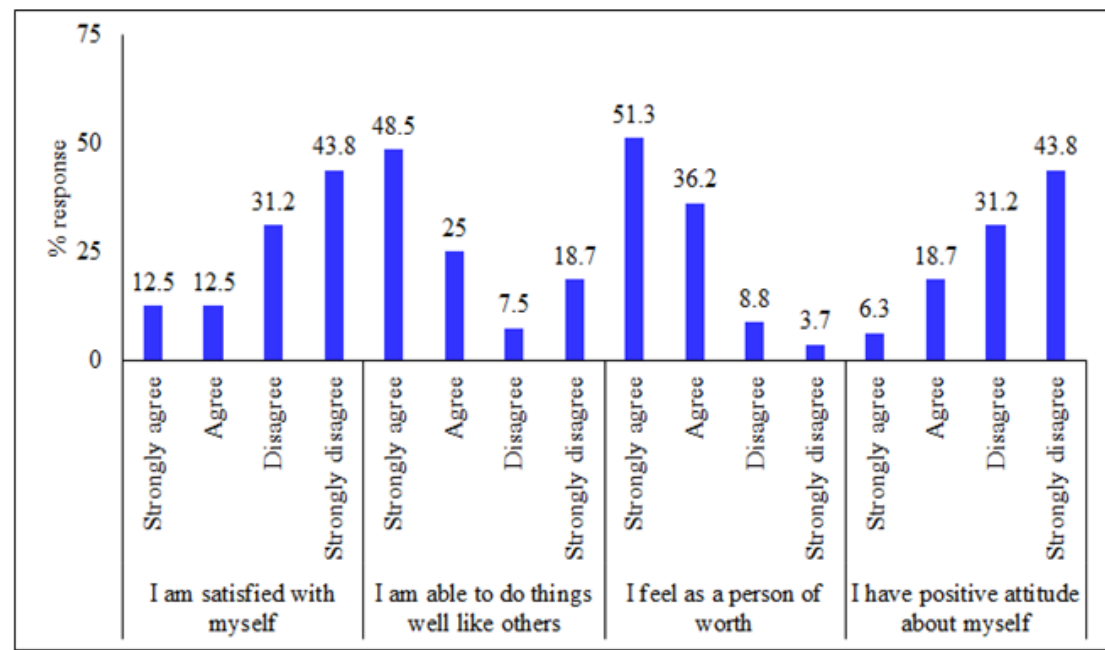

Fig. 3: Respondents' expression of good self-concept

When the respondents were asked of their expression about relationship with family and friends, $25.0 \%$ of them agreed that at times they thought that they were of no good, $47.5 \%$ strongly agreed, $8.8 \%$ disagree and $18.7 \%$ of the respondents strongly disagreed. Some of the respondents (36.2\%) agreed that they felt they do not have much to be proud of while the majority $(50 \%)$ strongly agreed, $7.5 \%$ disagreed and $3.5 \%$ of them strongly disagreed. About $57.5 \%$ agreed that they certainly felt useless at times, $37.5 \%$ strongly agreed, $3.8 \%$ disagreed, while only $1.2 \%$ strongly disagreed. Only a few of the respondents $(7.5 \%)$ agreed that they easily felt that they were failures, $3.7 \%$ strongly agreed, $38.8 \%$ disagreed $50.0 \%$ strongly disagreed (Fig. 4).

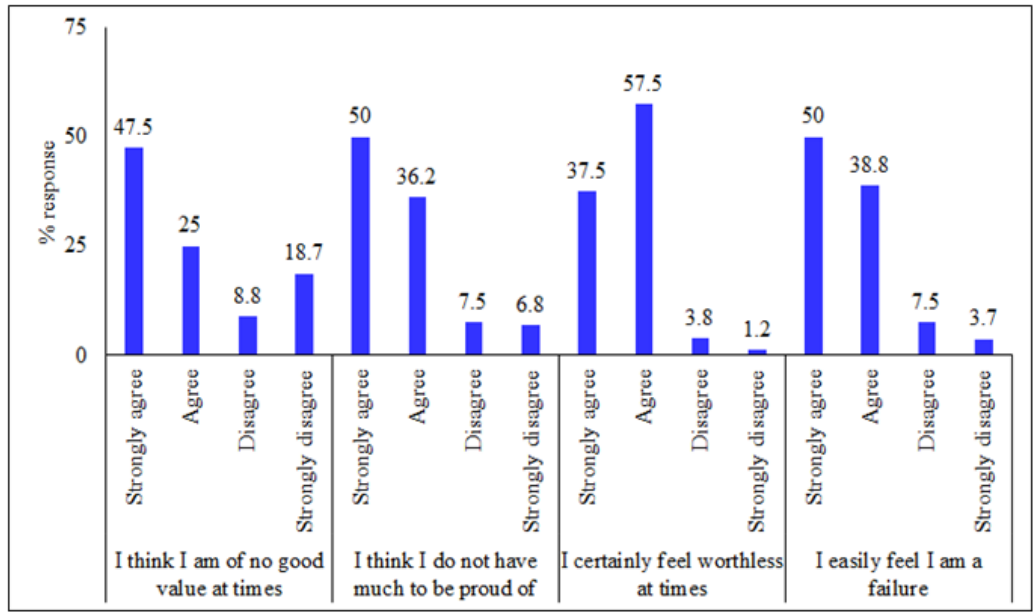

Fig. 4: Respondents' expression about relationship with family and friends 
With respect respondents' expression about relationship with family and friends, $6.2 \%$ of them agreed that they family and friends do listen to them, $26.4 \%$ strongly agreed, $31.1 \%$ disagreed, while $36.3 \%$ of the respondents strongly disagreed. Some of the respondents $(32.5 \%)$ agreed that they felt they have definite role in the family and among friends, majority (42.5\%) strongly agreed, $23.8 \%$ disagreed, while $26.2 \%$ of the respondents strongly disagreed. Few of the respondents $(10.0 \%)$ agreed that they family and friends do understand them, $15.0 \%$ strongly agreed, $27.5 \%$ disagreed, while majority of the respondents (47.5\%) strongly disagreed. Few of the respondents $(11.2 \%)$ agreed that they were carried along with issues within the family and friends, $16.3 \%$ strongly agreed, $25.0 \%$ disagreed, while majority of the respondents $(47.5 \%)$ strongly disagreed.

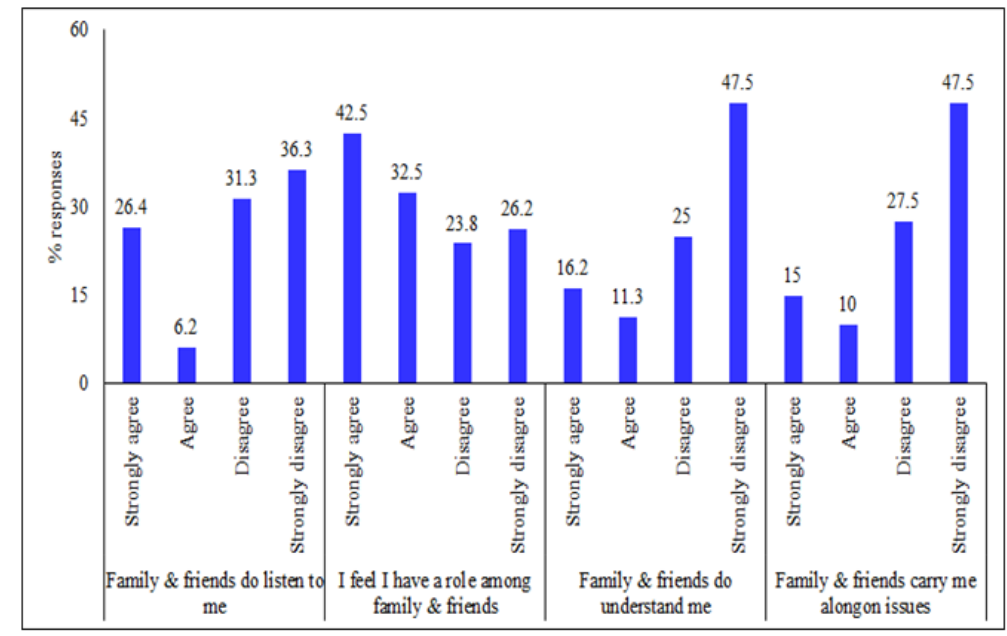

Fig. 5: Respondents expression about relationship with family and friends

When asked about their expression of social withdrawal, 5.0\% of the respondents agreed that they always in close contact with family and friends, $7.5 \%$ strongly agreed, $25.0 \%$ disagreed, while $62.5 \%$ of the respondents strongly disagreed. Some of the respondents $(36.2 \%)$ agreed that family and friends often accused them of not visiting them, $35.0 \%$ strongly agreed, $10 \%$ disagreed, while $6.0 \%$ of the respondents strongly disagreed. Majority of the respondents $(51.3 \%)$ strongly disagreed that they could not attend family and friends' social functions, 37.5\% disagreed, 5\% agreed while 6.2 strongly agreed. Some of the respondents $(48.7 \%)$ agreed that they often prefer to stay with husband rather than visiting family and friends, $48.7 \%$ strongly agreed, $1.3 \%$ disagreed, while few of the respondents $(2.5 \%)$ strongly disagreed. Some of the respondents $(36.3 \%)$ agreed that they often felt uncomfortable with most family and friends, $38.8 \%$ strongly agreed, $15.0 \%$ disagreed, while a few of them (10.0\%) strongly disagreed (Fig. 6).

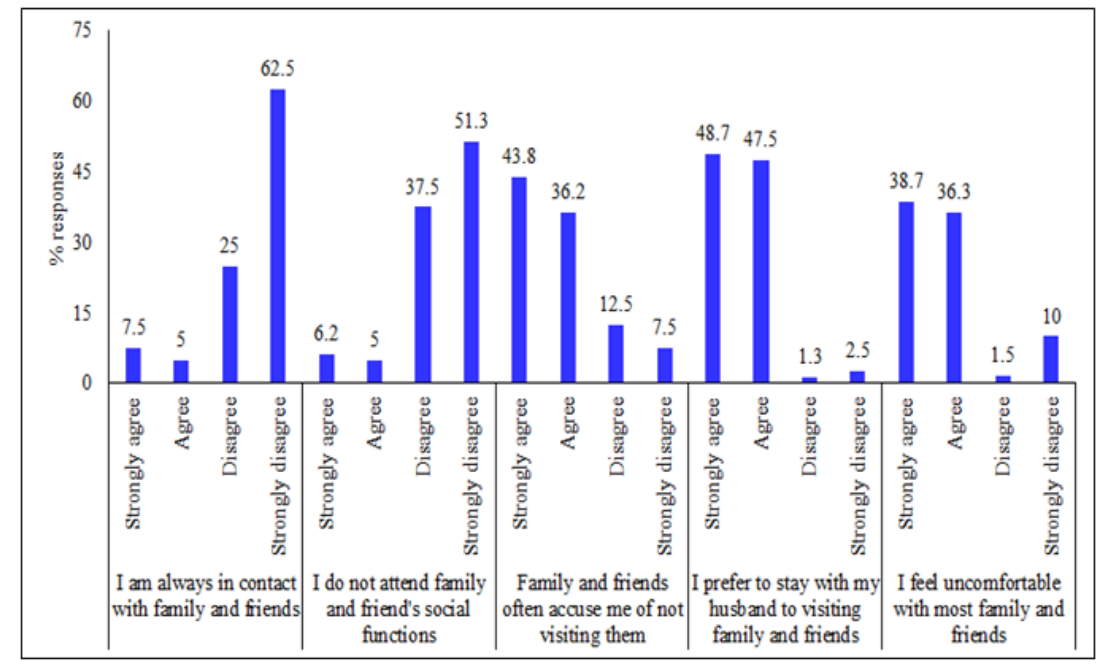

Fig. 6: Respondents' expression about social withdrawal

In terms of social support, some of the respondents (32.5\%) agreed that they had adequate emotional support from their husband, majority (43.8\%) strongly agreed, $18.7 \%$ disagreed, while $5.0 \%$ of the respondents strongly disagreed. Few of the respondents $(6.2 \%)$ agreed that they had adequate emotional support from their in-laws, $13.8 \%$ strongly agreed, $36.2 \%$ disagreed, while some of the respondents $(43.8 \%)$ strongly disagreed. Some of the respondents $(45.0 \%)$ agreed that they had adequate emotional support from the hospital, $50.0 \%$ strongly agreed, $3.8 \%$ disagreed, while $1.2 \%$ of the respondents strongly disagreed. Some of the respondents (42.5\%) agreed that they had adequate emotional support from their religious leader, $45.0 \%$ strongly agreed, $7.5 \%$ disagreed, while $4.5 \%$ of the respondents strongly disagreed (Fig. 7). 


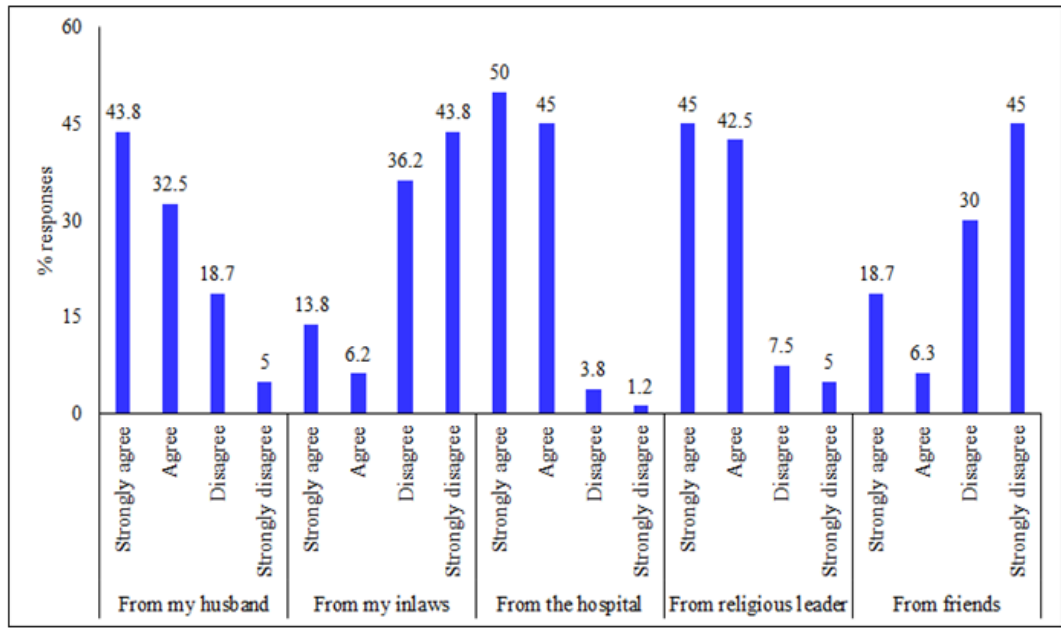

Fig. 7: Respondents' sources of social support

\section{Discussion}

The majority of the respondents in the study were within reproductive changes since their ages fell within the limits of 35-45 years $(50.0 \%)$ and 25-34years $(43.7 \%)$. The research setting was more populated with respondents who acquired tertiary education $(75.0 \%)$ than those with either primary or secondary education.

On the findings on the respondents' knowledge about the cause of infertility, the results revealed the majority of the respondents $(68.8 \%)$ claimed that infertility is caused by the use of contraceptives and most of them $(68.8 \%)$ had good knowledge on preventive measures of infertility. According to Smelter and Bare [9] [10], infertility is caused by physical problems in a man or woman's reproductive system, with around $25.0 \%$ of all cases of infertility arising from problems in a man's reproductive system while about $35.0 \%$ rise from abnormalities in a woman's system and in $10.0 \%$ of the cases, no cause can be found. Other factors that may contribute to infertility are age and poor sexual lifestyle. In most African cultures, infertility is an accepted reason for divorce, for a marriage is not considered to be fully consummated until children survive through infancy. Some attribute infertility to dissatisfaction of the ancestors and witchcraft, hence the belief that there is a need to appease the god of fertility before the problem can be solved [6].

From the finding on the psychosocial effects of infertility, the majority of the respondents $(75.0 \%)$ experienced dissatisfaction with themselves while $25.0 \%$ were satisfied. This observation corroborates the reports of Peterson et al.[5] [11]. In their reports, they indicated that infertile patients often experience emotional problems which result in continuous and recurring emotional feeling of inadequacy, guilt, loss, hopelessness, anxiety and a decrease in self-esteem.

With respect to the respondents' expression of feeling of worthlessness, the present study revealed that $72.5 \%$ of the respondents have expressed feeling of worthlessness at one point or the other. It is reported that female infertility produces social consequences for Africa women and these consequences are particularly profound for women as compared to men, regardless of the causes of infertility. Women are more often blamed for reproductive setbacks, which may lead to personal grief and frustration, social stigma and serious economic deprivation [4].

On the respondents' expression about relationship with family and friends, the study revealed that the majority of the respondents $(75.0 \%)$ indicated that family and friends did not understand with only a few $(11.2 \%)$ of them agreeing that they were carried along with issues within the family and friends. Similarly, only a few (5.0\%) of the respondents agreed that they were always in close contact with family and friends. Generally, the majority of the respondents $(87.5 \%)$ were not in close contact with family and friends. It is indicated that during the period of infertility, leisure satisfaction is impaired by the process of seeking treatment and by feelings of social isolation. Some evidence suggest that the characterization of infertile woman as totally immersed in the process of trying to become pregnant describes only as treatment seekers [12] [13] [14].

When investigating the respondents' perception on the preventive measures for infertility, the findings revealed that the majority of the respondents $(63.8 \%)$ had poor knowledge on preventive measures of infertility while $36.2 \%$ had poor knowledge. Shae-Lee [3] opined that quitting smoking and reducing alcohol intake are some of the preventive measures for infertility. Smoking has been reportedly linked to low sperm counts and sluggish sperm motility in men and increases miscarriage in women. Similarly, chronic alcohol abuse affects the fertility of both men and women trying to conceive either naturally or through infertility treatments. Alcohol is reported to be toxic to sperm, interfere with sexual performance, disrupts hormone balances and increases the risk of miscarriage.

\section{Conclusion and Recommendation}

In the study, it was discovered that the sociocultural factor greatly influenced respondents' self-esteem and caused them to isolate themselves. It was also inferred from the study that knowledge of respondents is also a factor influencing infertility.

The study further revealed that infertile women experienced social isolation and low self-esteem which was observed in clients with infertility over ten years. While societal sociocultural expectations from married women make infertile clients feel unfulfilled and useless, hence the need for more enlightenment and awareness are needed to change the society's misconception and bias beliefs as regards infertility. Also, the society should be encouraged to give adequate emotional support to the victims. 
Based on the findings of this research, it is pertinent to realize that there is a lot of work required on the side of nurses, majorly impacting knowledge and attitudinal change in women of child bearing age and the public as a whole.

The implications of the findings of this study for nursing practice are:

- Since the source of knowledge is a major factor influencing the perception of women of child bearing age towards infertility, Nurses should recognize that promoting attitudinal change in clients rest almost solely on them. This can be achieved by giving of effective enlightenment to clients concerning what infertility really is.

- Since religion also has a higher percentage of effect on women of child bearing ages' knowledge about infertility, Nurses need to help clear the society of all misconceptions concerning infertility.

- Women of child bearing age are always reluctant when it comes to screening and treatment for infertility. This attitude has however, rendered many couples infertile. In view of this, nurses should assist the women gain insight into their problems. The nurse should not partake in the stigmatization of infertile clients but should encourage members of the society to give psychological supports.

The limitations of this research study were the limited time frame for the study, uncooperative attitude of some the respondents' response to questionnaire. Based on the research findings, the researchers recommended that women of child bearing age, irrespective of their fertility status should be more enlightened to clear misconceptions on the causes of infertility since there is relationship between the source of health related information and the knowledge of women of child bearing age towards causes of infertility. Also, since psychological factors play an important role in the pathogenesis of infertility, giving of psychotherapeutic interventions are imperative.

\section{References}

[1] WHO, Infecundity, infertility, and childlessness in developing countries, Demographic and Health Surveys (DHS) Comparative reports No. 9. World Health Organization Sexual and Reproductive Health Report, 2004

[2] Kumar and Clark,Clinical medicine (Elseviar Saunders, 2004).

[3] M.A Shae-Lee,Perceptions of infertility and treatment stress in females as compared with males entering in vitro fertilization treatment, (India; Japee brother,2007).

[4] F. van Balen, and M.C. Inhorn, Definite involuntary childlessness: association between coping, social support and psychological distress, (India; Japee brother. 2004)

[5] B.D Peterson, C.R Newton, and K.H Rosen, Examining Congruence between Partners' Perceived Infertility-Related Stress and Its Relationship to Marital Adjustment and Depression in Infertile Couples, Family Process, 42, 2003, 59-70.

[6] D.D Atibinye,A.A Ariante, G.A Okeke, A.A Bibowei, O.L Umoh,M. Elino, R.I IgbansObele, A. Tiemo, and E.W Apiakise, Factors associated with acceptability of child adoption as a management option for infertility among females in Yenagoa Metropolis, Bayelsa State,International Journal of Development Research, 5(1), 2015, 3046-3049.

[7] F. van Balen, J. Verdurmen, and E. Ketting, Choices and motivations of infertile couples,Patient Education and Counselling, 31(1), 1997, 19-27.

[8] B. Neuman, and R.J Young, RJ, A model for teaching total person approach to patient problems, Nursing Research, 21, 1972, 264-269.

[9] S.C Smelter, and B.G Bare, Textbook of medical- surgical nursing (Linpincott, Williams and Wilkins USA, 2008).

[10] J. Namujju,Knowledge, attitudes and practices towards infertility among adults 18-40 years in Kalisizo, Rakai District in Uganda [Online], Assessed from;http://hdl.handle.net/10570/1705 . 2008.

[11] P.K Deka, and S. Sarma, Psychological aspects of infertility, British Journal of Medical Practitioners, 3(3), $2010,336$.

[12] D.C Parry, and K.J Shinew, The constraining impact of infertility on women's leisure life-styles, Leisure Sciences, 26(3), 2004, 295-308.

[13] Irene, and Steven,Prevalence of depressive and anxiety disorders in an assisted reproductive technique clinic, (Churchill Livingstone, 2008).

[14] A.L Greil, K. Slauson-Blevins, and J. McQuillan,The experience of infertility: A review of recent literature,Sociology of Health and Illness, 32(1), $2010,140-162$. 